\title{
A cocoon immunisation strategy against pertussis for infants: does it make sense for Ontario?
}

G H Lim (gillian.lim@oahpp.ca) ${ }^{1}$, S L Deeks ${ }^{1,2}$, N S Crowcroft ${ }^{1,2}$

1. Public Health Ontario, Toronto, Canada

2. University of Toronto, Toronto, Canada

Lim GH, Deeks SL, Crowcroft NS. A cocoon immunisation strategy against pertussis for infants: does it make sense for Ontario? . Euro Surveill.

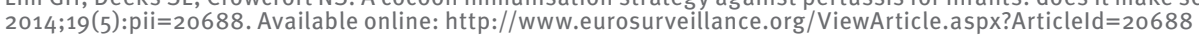

Pertussis deaths occur primarily among infants who have not been fully immunised. In Ontario, Canada, an adult booster dose was recently added to the publicly funded immunisation programme. We applied number-needed-to-treat analyses to estimate the number of adults that would need to be vaccinated (NNV) to prevent pertussis disease, hospitalisation and death among infants if a cocoon strategy were implemented. $N N V=1 /\left(P_{M} X R\right)+1 /\left(P_{F} X R\right)$, where $P_{M}, P_{F}$ (proportion of infants infected by mothers, fathers) were sourced from several studies. Rates of disease, hospitalisation or death $(R)$ were derived from Ontario's reportable disease data and Discharge Abstract Database. After adjusting for under-reporting, the NNV to prevent one case, hospitalisation or death from pertussis was between 500-6,400, 12,000-63,000 and 1.1-12.8 million, respectively. Without adjustment, NNV increased to 5,000-60,000, 55,000-297,000 and 2.5-30.2 million, respectively. Rarer outcomes were associated with higher NNV. These analyses demonstrate the relative inefficiency of a cocoon strategy in Ontario, which has a well-established universal immunisation programme with relatively high coverage and low disease incidence. Other jurisdictions considering a cocoon programme should consider their local epidemiology.

\section{Introduction}

Pertussis is an infectious respiratory disease caused by Bordetella pertussis, typically presenting with a paroxysmal cough followed by a characteristic 'whoop' sound. Young infants, adolescents and adults are less likely to present with typical symptoms, which leads to under-diagnosis by physicians, who may fail to consider the diagnosis [1]. While disease occurs in all age groups, complications occur most frequently in infants too young to have begun or completed their primary immunisation series, particularly among those under four months of age [2]. The case-fatality ratio (CFR) among infants under one year of age is estimated to be $0.2 \%$ [3] in countries with low mortality, though it can reach $3 \%[4]$.

In Ontario, Canada, pertussis vaccines have been available since 1943 and are currently offered as combination vaccines. Diphtheria and tetanus toxoids, acellular pertussis, inactivated poliomyelitis and Haemophilus influenzae type b (DTaP-IPV-Hib) is administered as a primary series at 2, 4 and 6 months with a booster dose at 18 months of age. A second booster of DTaP-IPV is administered at 4-6 years. Since 2003, an adolescent acellular pertussis booster dose using the adolescent/adult formulation (Tdap) has also been offered at 14-16 years, with coverage among 17-year olds estimated at $67.7 \%$ [5]. On 8 August 2011, a single dose of Tdap vaccine (Adacel by Sanofi Pasteur or Boostrix by GlaxoSmithKline) was publicly funded for adults aged 19 to 64 years who had not previously received an adolescent booster.

Parents, siblings and other household contacts are frequently identified as the primary source of infection among infants with pertussis [6-16]. Cocooning refers to the vaccination of mothers and other contacts of newborns and infants in order to prevent the transmission of pertussis to infants who may not have completed their primary vaccination series. Since 2012 in the United States (US), the Advisory Council on Immunization Practices (ACIP) has recommended a dose of Tdap during every pregnancy, irrespective of previous vaccination history [17]. In Canada, the National Advisory Committee on Immunization (NACl) recommends a universal adult immunisation programme) [18]. New Brunswick is the only Canadian jurisdiction to recommend and to have implemented a cocoon programme where parents are entitled to receive publiclyfunded Tdap vaccine since 1 January 2011.

We applied the concept of 'number needed to treat' to estimate the number of adults that would need to be vaccinated (NNV) to prevent one case of disease, hospitalisation and death among infants if a cocoon strategy were implemented in Ontario.

\section{Methods}

The number of mothers and fathers that would need to be vaccinated to prevent one case, hospitalisation or death due to pertussis among infants (defined as 
children less than one year of age) was estimated using the following formula:

$$
\begin{aligned}
& N N V_{\text {total }}=N N V_{\text {mother }}+N N V_{\text {father }} \\
& =\frac{1}{A R_{\text {mother }} \times V E}+\frac{1}{A R_{\text {father }} \times V E} \\
& =\frac{1}{\left\{\text { Incidence } \% \text { Infected }_{\text {mother }}\right\} \times V E}
\end{aligned}
$$

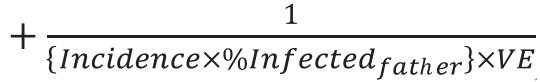

where

- $A R=$ attributable risk due to the mother or father, as specified

- $\mathrm{VE}=$ vaccine effectiveness

- incidence $=$ rate of disease, hospitalisation or death among infants aged under one year

- $\%$ infected $=$ the proportion of infants aged under one year who were infected by their mother or father, as specified.

Vaccine effectiveness (VE) was generally assumed to be $85 \%$ except where noted. Estimates of incidence varied depending on the outcome of interest. Rates of disease were based on confirmed cases of pertussis in infants under one year of age, as reported in Ontario's integrated Public Health Information System (iPHIS) between 1 January 2005 and 31 December 2009. In 2009, the case definition was changed so that clinically compatible illness, in addition to laboratory detection of pertussis, was required to meet the definition for a confirmed case. This more specific definition will have resulted in fewer confirmed cases. Mortality rates were determined by applying the CFR of $0.2 \%$ [3] to the rates of disease. Hospitalisation rates were determined using data from the Discharge Abstract Database maintained by the Canadian Institute for Health Information. Infants who were discharged between 2005 and 2009 were included in this analysis. Patients for whom pertussis was determined to have contributed most significantly to their hospitalisation (i.e. most responsible diagnosis) were identified by selecting a code of $A 37.0$ under the Canadian Enhancement to the 10th revision of the International Statistical Classification of Diseases and Related Health Problems (ICD-10-CA) [19]. Using methodology consistent with the Ontario Burden of Infectious Diseases (ONBOIDS) report, rates of disease (and consequently death) were inflated by a factor of 9.4 to adjust for the under-reporting of cases [4]. Since hospitalised cases and deaths were less likely to be under-reported, hospitalisation and mortality rates were only inflated by factors of 4.7 and 2.35 , respectively (i.e. multiplying the original inflation factor of 9.4 by 0.5 and $0.5^{2}$ ). To account for yearly fluctuations in incidence, the minimum, maximum and average rates during the study period were used. Demographic data from Statistics Canada, accessed through intelliHealth, were used to calculate incidence. As denominator data by month were not available for infants under one year of age, we assumed equal population distribution over the first year of life to calculate rates among infants less than four months of age. The introduction of realtime PCR testing in 2005 may have contributed to the increase in cases observed in subsequent years.

To determine the proportion of infants who were infected by their mother or father (\% infected), several studies were reviewed. While numerous studies have been conducted to explore the role of adults and siblings in transmitting infection to infants in Australia [6,7], the Netherlands [8], Canada [9], the US [10-12], England [13] and France [14,15], including a recent review [16], only a few studies published the data necessary to determine the proportion of infants (including those for whom the source of infection was unknown) who were infected by the mother or father $[6,8,10]$. In an additional study [13], the required data were obtained from the author (data not shown). Table 1 presents the range of mother- and father-specific estimates from these studies, and shows the impact of including and excluding cases whose source of infection was unknown. When cases with unknown sources of infection were included, the proportion of infants who were infected by their mother and father ranged between $14 \%$ and $21 \%$, and $6 \%$ and $11 \%$, respectively. When unknowns were excluded, the proportion infected by their mother and father ranged between $20 \%$ and $41 \%$, and $12 \%$ and $18 \%$, respectively. Estimates from the Dutch study were excluded since the methodology used to determine sources of infection was not comparable to the other studies (no determination of a unique source of infection was made, whereas this was defined in the other studies).

\section{Results}

Between 2005 and 2009, 844 confirmed cases of pertussis among infants less than one year old were reported through iPHIS in Ontario. Of these, $49.2 \%$ $(n=415)$ of cases occurred in infants less than four months old. The unadjusted incidence of disease ranged between 46.4 and 186.9 cases per 100,000 infants per year, while the hospitalisation rate ranged between 9.4 and 17.2 cases per 100,000 infants per year (Figure 1). Fluctuations observed in pertussis incidence rates were not reflected in the hospitalisation rates. Among infants less than four months old, disease incidence and hospitalisation rates ranged between 75.0 and 269.5 , and 21.9 and 38.1 per 100,000 infants, respectively.

NNV estimates for a range of each outcome of disease, hospitalisation and death are provided in Tables 2, 3 and 4 , respectively. In addition to the total number of parents that would need to be vaccinated $\left(\mathrm{NNV}_{\text {total }}\right)$, which takes into account the risk of infection by mothers and fathers combined, the number of women that would need to be vaccinated if the programme was targeted solely to mothers is also provided ( $\left.\mathrm{NNV}_{\text {mother }}\right)$, 
TABLE 1

Summary of studies used to derive estimates of percentage of infection among infants less than one year of age

\begin{tabular}{|c|c|c|c|c|c|c|}
\hline \multirow{3}{*}{ Country } & \multirow{3}{*}{ Year } & \multirow{3}{*}{ Study population } & \multicolumn{4}{|c|}{ Source of infection } \\
\hline & & & \multicolumn{2}{|c|}{ Mother } & \multicolumn{2}{|c|}{ Father } \\
\hline & & & Number & Percentage $^{a}$ & Number & Percentage $\mathrm{a}^{\mathrm{a}}$ \\
\hline Australia [6] & 2009 & $\begin{array}{c}\text { Laboratory-confirmed } \\
\text { outbreak cases }<12 \\
\text { months }\end{array}$ & 13 & $14-20$ & 8 & $8-12$ \\
\hline Netherlands [8] & $2006-2008$ & $\begin{array}{l}\text { Laboratory-confirmed } \\
\text { hospitalisations \& } 6 \\
\text { months }\end{array}$ & 52 & 54 & 23 & 24 \\
\hline United States [10] & $1999-2002$ & Notifications $<12$ months & 84 & $14-32$ & 39 & $6-15$ \\
\hline England ${ }^{b}$ & $1998-2000$ & $\begin{array}{c}\text { Laboratory-confirmed } \\
\text { hospitalisations }<5 \\
\text { months }\end{array}$ & $7^{c}$ & $21-41$ & 3 & $11-18$ \\
\hline
\end{tabular}

a Percentage range reflects percentage including unknowns to percentage excluding unknowns.

b Unpublished data.

' Includes one case whose source of infection was either the mother or father.

as some programmes have considered this strategy as mothers are often easier to reach. Because mothers are more frequently identified as the source of infection for an infant relative to the father (Table 1), estimates of $\mathrm{NNV}_{\text {mother }}$ were considerably smaller than estimates of $\mathrm{NNV}_{\text {total }}$.

A range of estimates of pertussis incidence, hospitalisation and mortality rates among infants were assumed, and adjustments for under-reporting, as described in the methods, were made. As expected, the NNV to prevent a case of pertussis was less than that needed to prevent hospitalisation and death. For example, using the minimum inflated rates while assuming $85 \%$ VE and $14 \%$ and $6 \%$ of infants were infected by their mothers and fathers, respectively, the $N_{N V}$ total estimate to prevent one pertussis case, hospitalisation and death was approximately $6,400,63,000$, and 12.8

\section{FIGURE 1}

Unadjusted rates of disease and hospitalisation due to pertussis among infants less than one year of age, Ontario, 2005-2009

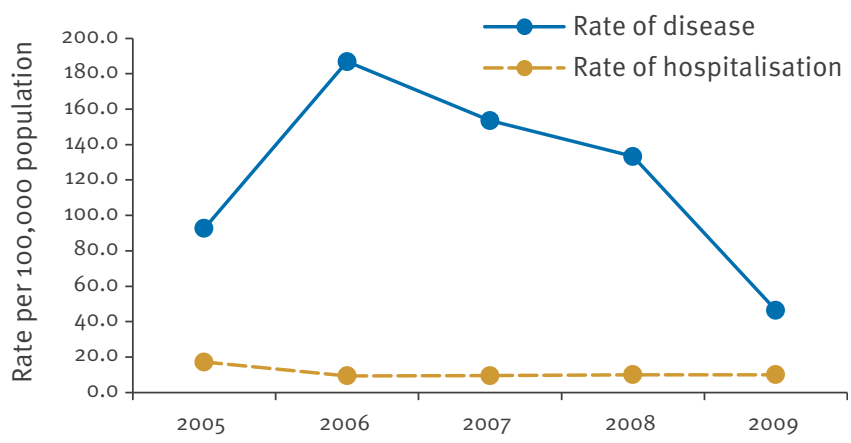

million, respectively. For comparison, if VE was reduced to $80 \%, \mathrm{NNV}_{\text {total }}$ estimates increased $(6,800,67,000$, and 13.6 million respectively, data not shown), while increasing VE to $90 \%$ reduced $\mathrm{NNV}_{\text {total }}$ estimates $(6,100$, 60,000 , and 12.1 million respectively, data not shown). If no adjustments were made for under-reporting, the NNV increased by the magnitude of the inflation factor. Conversely, as the mother- and father-specific estimates of risk increased, the NNV estimates decreased. These estimates of risk of infection were influenced by the inclusion or exclusion of cases with an unknown source of infection in the denominator. Excluding these cases inflated the mother- and father-specific risks, which resulted in a decrease in the corresponding NNV estimates.

Using the average inflated rates observed between 2005 and 2009, between 800 and 2,400 individuals would need to be vaccinated to prevent one case of pertussis; 18,000 and 53,000 individuals would need to be vaccinated to prevent one hospitalisation; 1.6 and 4.9 million individuals would need to be vaccinated to prevent a death. The estimates varied according to the proportion of infants infected by a mother or father assumed, and whether unknown sources of infection were included. Further limiting the analysis to prevent a case, hospitalisation or death in an infant less than four months old resulted in a reduction in NNV due to the increased frequency of outcomes in this younger age group (600-1,600, 7,000-21,000 and 1.1-3.3 million, respectively, data not shown).

Comparisons of the proportion of infants infected by parents in Table 1 yielded a ratio of $1.7-2.3$ to 1 for mothers to fathers. Therefore, assuming a 2:1 ratio (i.e. infants are twice as likely to be infected by a mother than a father), Figure 2 illustrates the relationship 
TABLE 2

Estimated number needed to vaccinate to prevent one pertussis case among infants less than one year of age, Ontario

\begin{tabular}{|c|c|c|c|c|c|c|c|c|}
\hline \multirow{2}{*}{$\begin{array}{l}\text { Incidence } \\
\text { rate per } \\
100,000 \\
\text { population }\end{array}$} & \multicolumn{4}{|c|}{ Unknown sources included } & \multicolumn{4}{|c|}{ Unknown sources excluded } \\
\hline & Mother (\%) ${ }^{\mathrm{a}}$ & Father $(\%)^{a}$ & $N N V_{\text {total }}{ }^{b}$ & $N N V_{\text {mother }}{ }^{c}$ & Mother (\%)a & Father (\%)a & $N_{N V_{\text {total }}}^{\mathrm{b}}$ & $N N V_{\text {mother }}{ }^{c}$ \\
\hline \multicolumn{9}{|c|}{ Unadjusted rates } \\
\hline \multirow{4}{*}{$\begin{array}{l}46.4 \\
\text { (minimum) }\end{array}$} & 14 & 6 & 60,345 & \multirow{2}{*}{18,104} & 20 & 12 & 33,793 & \multirow{2}{*}{12,672} \\
\hline & 14 & 11 & 41,144 & & 20 & 18 & 26,753 & \\
\hline & 21 & 6 & 54,311 & \multirow{2}{*}{12,069} & 41 & 12 & 27,303 & \multirow{2}{*}{6,182} \\
\hline & 21 & 11 & 35,110 & & 41 & 18 & 20,262 & \\
\hline \multirow{4}{*}{$\begin{array}{l}122.6 \\
\text { (average) }\end{array}$} & 14 & 6 & 22,855 & \multirow{2}{*}{6,857} & 20 & 12 & 12,799 & \multirow{2}{*}{4,800} \\
\hline & 14 & 11 & 15,583 & & 20 & 18 & 10,133 & \\
\hline & 21 & 6 & 20,570 & \multirow{2}{*}{4,571} & 41 & 12 & 10,341 & \multirow{2}{*}{2,341} \\
\hline & 21 & 11 & 13,298 & & 41 & 18 & 7,674 & \\
\hline \multirow{4}{*}{$\begin{array}{l}186.9 \\
\text { (maximum) }\end{array}$} & 14 & 6 & 14,986 & \multirow{2}{*}{4,496} & 20 & 12 & 8,392 & \multirow{2}{*}{3,147} \\
\hline & 14 & 11 & 10,218 & & 20 & 18 & 6,644 & \\
\hline & 21 & 6 & 13,488 & \multirow{2}{*}{2,997} & 41 & 12 & 6,780 & \multirow{2}{*}{1,535} \\
\hline & 21 & 11 & 8,719 & & 41 & 18 & 5,032 & \\
\hline \multicolumn{9}{|c|}{ Inflated rates ${ }^{d}$} \\
\hline \multirow{4}{*}{$\begin{array}{l}436.3 \\
\text { (minimum) }\end{array}$} & 14 & 6 & 6,420 & \multirow{2}{*}{1,926} & 20 & 12 & 3,595 & \multirow{2}{*}{1,348} \\
\hline & 14 & 11 & 4,377 & & 20 & 18 & 2,846 & \\
\hline & 21 & 6 & 5,778 & \multirow{2}{*}{1,284} & 41 & 12 & 2,905 & \multirow{2}{*}{658} \\
\hline & 21 & 11 & 3,735 & & 41 & 18 & 2,156 & \\
\hline \multirow{4}{*}{$\begin{array}{l}1,152.1 \\
\text { (average) }\end{array}$} & 14 & 6 & 2,431 & \multirow{2}{*}{729} & 20 & 12 & 1,362 & \multirow{2}{*}{511} \\
\hline & 14 & 11 & 1,658 & & 20 & 18 & 1,078 & \\
\hline & 21 & 6 & 2,188 & \multirow{2}{*}{486} & 41 & 12 & 1,100 & \multirow{2}{*}{249} \\
\hline & 21 & 11 & 1,415 & & 41 & 18 & 816 & \\
\hline \multirow{4}{*}{$\begin{array}{l}1,757.0 \\
\text { (maximum) }\end{array}$} & 14 & 6 & 1,594 & & 20 & 12 & 893 & \\
\hline & 14 & 11 & 1,087 & 478 & 20 & 18 & 707 & 335 \\
\hline & 21 & 6 & 1,435 & & 41 & 12 & 721 & \\
\hline & 21 & 11 & 928 & 319 & 41 & 18 & 535 & 163 \\
\hline
\end{tabular}

NNV: number needed to vaccinate.

a A range of the proportion of infants infected by mothers and fathers is provided based on estimates presented in Table 1.

b Total number needed to vaccinate, including mothers and fathers.

Number needed to vaccinate, including mothers only.

d Inflated by factor of 9.4 to adjust for under-reporting.

between $\mathrm{NNV}_{\text {total }}$ and the proportion of infants infected by parents, for cases of disease, hospitalisations and deaths. This approach allows us to hypothesise about the overall parental risk, yet still account for motherand father-specific estimates. Assuming $40 \%$ of infants are infected by parents and using the average inflated rate, the $\mathrm{NNV}_{\text {total }}$ estimates to prevent one case, hospitalisation and death due to pertussis is approximately 1,100, 25,000 and 2.3 million individuals, respectively.

\section{Discussion}

The practice of applying the concept of 'number needed to treat' for vaccine-preventable diseases [20-25] including pertussis $[26,27]$ is not new. In the context of rabies, it was estimated that up to 2.7 million people would need to be vaccinated to prevent a single case of human rabies at associated costs of up to 2 billion CAD (1.3 billion EUR) [20]. The example of rabies illustrates how the context is important; the outcome of rabies infection is much more severe than pertussis with a CFR of $100 \%$. In this analysis, we have demonstrated that NNV estimates for pertussis vary greatly depending on the frequency of the outcome including the target age group, the degree of under-reporting believed to be in existence, assumed VE and the estimated proportion of infants infected by the mother and father. In 
TABLE 3

Estimated number needed to vaccinate to prevent one pertussis hospitalisation among infants less than one year of age, Ontario

\begin{tabular}{|c|c|c|c|c|c|c|c|c|}
\hline \multirow{2}{*}{$\begin{array}{l}\text { Hospitalisation } \\
\text { rate per } 100,000 \\
\text { population }\end{array}$} & \multicolumn{4}{|c|}{ Unknown sources included } & \multicolumn{4}{|c|}{ Unknown sources excluded } \\
\hline & Mother $(\%)^{\mathrm{a}}$ & Father $(\%)^{a}$ & $N N V_{\text {total }^{b}}$ & $N N V_{\text {mother }}{ }^{c}$ & Mother (\%) & Father $(\%)^{a}$ & $N N V_{\text {total }^{b}}$ & $N N V_{\text {mother }}{ }^{c}$ \\
\hline \multicolumn{9}{|l|}{ Unadjusted rates } \\
\hline \multirow{4}{*}{$\begin{array}{l}9.4 \\
\text { (minimum) }\end{array}$} & 14 & 6 & 297,423 & \multirow{2}{*}{89,227} & 20 & 12 & 166,557 & \multirow{2}{*}{62,459} \\
\hline & 14 & 11 & 202,788 & & 20 & 18 & 131,858 & \\
\hline & 21 & 6 & 267,681 & \multirow{2}{*}{59,485} & 41 & 12 & 134,566 & \multirow{2}{*}{30,468} \\
\hline & 21 & 11 & 173,046 & & 41 & 18 & 99,866 & \\
\hline \multirow{4}{*}{$\begin{array}{l}11.2 \\
\text { (average) }\end{array}$} & 14 & 6 & 249,771 & \multirow{2}{*}{74,931} & 20 & 12 & 139,872 & \multirow{2}{*}{52,452} \\
\hline & 14 & 11 & 170,298 & & 20 & 18 & 110,732 & \\
\hline & 21 & 6 & 224,794 & \multirow{2}{*}{49,954} & 41 & 12 & 113,006 & \multirow{2}{*}{25,586} \\
\hline & 21 & 11 & 145,321 & & 41 & 18 & 83,866 & \\
\hline \multirow{4}{*}{$\begin{array}{l}17.2 \\
\text { (maximum) }\end{array}$} & 14 & 6 & 163,137 & \multirow{2}{*}{48,941} & 20 & 12 & 91,357 & \multirow{2}{*}{34,259} \\
\hline & 14 & 11 & 111,230 & & 20 & 18 & 72,324 & \\
\hline & 21 & 6 & 146,824 & \multirow{2}{*}{32,627} & 41 & 12 & 73,810 & \multirow{2}{*}{16,712} \\
\hline & 21 & 11 & 94,916 & & 41 & 18 & 54,777 & \\
\hline \multicolumn{9}{|l|}{ Inflated rates ${ }^{d}$} \\
\hline \multirow{4}{*}{$\begin{array}{l}44 \cdot 3 \\
\text { (minimum) }\end{array}$} & 14 & 6 & 63,281 & \multirow{2}{*}{18,984} & 20 & 12 & 35,438 & \multirow{2}{*}{13,289} \\
\hline & 14 & 11 & 43,146 & & 20 & 18 & 28,055 & \\
\hline & 21 & 6 & 56,953 & \multirow{2}{*}{12,656} & 41 & 12 & 28,631 & \multirow{2}{*}{6,482} \\
\hline & 21 & 11 & 36,818 & & 41 & 18 & 21,248 & \\
\hline \multirow{4}{*}{$\begin{array}{l}52.7 \\
\text { (average) }\end{array}$} & 14 & 6 & 53,143 & \multirow{2}{*}{15,943} & 20 & 12 & 29,760 & \multirow{2}{*}{11,160} \\
\hline & 14 & 11 & 36,234 & & 20 & 18 & 23,560 & \\
\hline & 21 & 6 & 47,828 & 10.620 & 41 & 12 & 24,044 & 5.444 \\
\hline & 21 & 11 & 30,919 & 0,028 & 41 & 18 & 17,844 & 3,444 \\
\hline \multirow{4}{*}{$\begin{array}{l}80.7 \\
\text { (maximum) }\end{array}$} & 14 & 6 & 34,710 & \multirow{2}{*}{10,413} & 20 & 12 & 19,438 & \multirow{2}{*}{7,289} \\
\hline & 14 & 11 & 23,666 & & 20 & 18 & 15,388 & \\
\hline & 21 & 6 & 31,239 & 602 & 41 & 12 & 15,704 & $35{ }^{6}$ \\
\hline & 21 & 11 & 20,195 & 0,942 & 41 & 18 & 11,655 & 3,550 \\
\hline
\end{tabular}

NNV: number needed to vaccinate.

a A range of the proportion of infants infected by mothers and fathers is provided based on estimates presented in Table 1.

b Total number needed to vaccinate, including mothers and fathers.

c Number needed to vaccinate, including mothers only.

d Inflated by factor of 4.7 to adjust for under-reporting.

particular, due to the decreased frequency of infants whose source of infection was stated as the father, the inclusion of fathers resulted in a large increase in the NNV estimates. Although the concept is not new, there is no acceptable threshold for the NNV. It serves as an intuitive and simple measure that can be used to compare interventions in a limited way.

Regardless of the methodology or inflation factor used, our NNV analyses demonstrate that estimates vary greatly depending on the frequency of the outcome of interest. Therefore, the objectives of implementing a cocoon immunisation strategy must be carefully considered. If the objective of the programme is to prevent pertussis in the population in general, then a universal strategy should be considered. Otherwise, if the objective of the programme is to prevent deaths due to pertussis, a large number of adults would need to be vaccinated. Similarly, in order to prevent an infant case or infant hospitalisation due to pertussis, then regardless of the degree to which under-reporting is believed 
TABLE 4

Estimated number needed to vaccinate to prevent one pertussis death among infants less than one year of age, Ontario

\begin{tabular}{|c|c|c|c|c|c|c|c|c|}
\hline \multirow{2}{*}{$\begin{array}{l}\text { Hospitalisation } \\
\text { rate per } 100,000 \\
\text { population }\end{array}$} & \multicolumn{4}{|c|}{ Unknown sources included } & \multicolumn{4}{|c|}{ Unknown sources excluded } \\
\hline & Mother $(\%)^{\mathrm{a}}$ & Father (\%)a & $\mathrm{NNV}_{\text {total }^{\mathrm{b}}}$ & $N N V_{\text {mother }}{ }^{c}$ & Mother (\%) & Father (\%)a & $\mathrm{NNV}_{\text {total }^{\mathrm{b}}}$ & $N N V_{\text {mother }}{ }^{c}$ \\
\hline \multicolumn{9}{|l|}{ Unadjusted rates } \\
\hline \multirow{4}{*}{$\begin{array}{l}0.093 \\
\text { (minimum) }\end{array}$} & 14 & 6 & $30,172,592$ & \multirow{2}{*}{$9,051,778$} & 20 & 12 & $16,896,652$ & \multirow{2}{*}{$6,336,244$} \\
\hline & 14 & 11 & $20,572,222$ & & 20 & 18 & $13,376,516$ & \\
\hline & 21 & 6 & $27,155,333$ & \multirow{2}{*}{$6,034,518$} & 41 & 12 & $13,651,258$ & \multirow{2}{*}{$3,090,851$} \\
\hline & 21 & 11 & $17,554,963$ & & 41 & 18 & $10,131,122$ & \\
\hline \multirow{4}{*}{$\begin{array}{l}0.245 \\
\text { (average) }\end{array}$} & 14 & 6 & $11,427,661$ & \multirow{2}{*}{$3,428,298$} & 20 & 12 & $6,399,490$ & \multirow{2}{*}{$2,399,809$} \\
\hline & 14 & 11 & $7,791,587$ & & 20 & 18 & $5,066,263$ & \\
\hline & 21 & 6 & $10,284,895$ & \multirow{2}{*}{$2,285,532$} & 41 & 12 & $5,170,320$ & \multirow{2}{*}{$1,170,638$} \\
\hline & 21 & 11 & $6,648,821$ & & 41 & 18 & $3,837,093$ & \\
\hline \multirow{4}{*}{$\begin{array}{l}0.374 \\
\text { (maximum) }\end{array}$} & 14 & 6 & $7,493,214$ & \multirow{2}{*}{$2,247,964$} & 20 & 12 & $4,196,200$ & \multirow{2}{*}{$1,573,575$} \\
\hline & 14 & 11 & $5,109,010$ & & 20 & 18 & $3,321,992$ & \\
\hline & 21 & 6 & $6,743,893$ & \multirow{2}{*}{$1,498,643$} & 41 & 12 & $3,390,223$ & \multirow{2}{*}{767,598} \\
\hline & 21 & 11 & $4,359,688$ & & 41 & 18 & $2,516,014$ & \\
\hline \multicolumn{9}{|l|}{ Inflated rates ${ }^{d}$} \\
\hline \multirow{4}{*}{$\begin{array}{l}0.218 \\
\text { (minimum) }\end{array}$} & 14 & 6 & $12,839,401$ & \multirow{2}{*}{$3,851,820$} & 20 & 12 & $7,190,065$ & \multirow{2}{*}{$2,696,274$} \\
\hline & 14 & 11 & $8,754,137$ & & 20 & 18 & $5,692,134$ & \\
\hline & 21 & 6 & $11,555,461$ & \multirow{2}{*}{$2,567,880$} & 41 & 12 & $5,809,046$ & \multirow{2}{*}{$1,315,256$} \\
\hline & 21 & 11 & $7,470,197$ & & 41 & 18 & $4,311,116$ & \\
\hline \multirow{4}{*}{$\begin{array}{l}0.576 \\
\text { (average) }\end{array}$} & 14 & 6 & $4,862,834$ & \multirow{2}{*}{$1,458,850$} & 20 & 12 & $2,723,187$ & \multirow{2}{*}{$1,021,195$} \\
\hline & 14 & 11 & $3,315,569$ & & 20 & 18 & $2,155,857$ & \\
\hline & 21 & 6 & $4,376,551$ & 072567 & 41 & 12 & $2,200,136$ & 10811 \\
\hline & 21 & 11 & $2,829,285$ & 912,507 & 41 & 18 & $1,632,805$ & 490,144 \\
\hline \multirow{4}{*}{$\begin{array}{l}0.878 \\
\text { (maximum) }\end{array}$} & 14 & 6 & $3,188,602$ & \multirow{2}{*}{956,581} & 20 & 12 & $1,785,617$ & \multirow{2}{*}{669,606} \\
\hline & 14 & 11 & $2,174,047$ & & 20 & 18 & $1,413,613$ & \\
\hline & 21 & 6 & $2,869,742$ & & 41 & 12 & $1,442,648$ & \\
\hline & 21 & 11 & $1,855,187$ & $03 /, 720$ & 41 & 18 & $1,070,644$ & 326,037 \\
\hline
\end{tabular}

NNV: number needed to vaccinate.

a A range of the proportion of infants infected by mothers and fathers is provided based on estimates presented in Table 1.

b Total number needed to vaccinate, including mothers and fathers.

Number needed to vaccinate, including mothers only.

d Inflated by factor of 2.35 to adjust for under-reporting.

to exist, up to 298,000 individuals would need to be vaccinated (this represents approximately $6.4 \%$ of the adult (20-44 years old) population in Ontario). Another Canadian study using different methodology also reported extremely high NNV to prevent deaths and serious outcomes, and also concluded that a parental cocoon programme was inefficient and resource intensive [27]. A similar conclusion was reached by authors of a study conducted in Italy, which also has a low incidence of disease [28]. It is important to note that our estimates were derived based on the epidemiology of pertussis in Ontario which has a well-established universal immunisation programme with relatively high coverage and low disease incidence. Other jurisdictions considering a cocoon programme should consider their local epidemiology.

Currently, data evaluating the effectiveness of a cocoon strategy are limited. Since the implementation of such a strategy in the US in 2006, data from 
two small studies have been reported with conflicting results. One study documented a $50 \%$ decline in the incidence of pertussis in hospitals with a post-partum Tdap vaccination policy in $2006(n=48)$, while a 20\% increase was observed among hospitals that did not have such a policy $(n=145)$ [29]. In contrast, Castagnini et al. [30] found no difference in the rates of illness, length of stay or mortality in infants under six months of age when post-partum women were vaccinated prior to discharge. The authors recommended that all household and key contacts of newborns should be immunised instead.

Additional factors that are important to consider with respect to the cocoon strategy include the feasibility of achieving satisfactory uptake using this approach, its cost-effectiveness, and impact on health equity. A cocoon strategy for mothers may offer benefits that accumulate through subsequent pregnancies depending on the duration of protection from the vaccine and may also result in greater uptake within this population due to the targeted nature of the programme and accessibility of the population. However the recent addition of an adult pertussis booster to the immunisation programme in Ontario has the added benefits of providing protection to other close contacts of infants, such as fathers, grandparents and other adult caregivers. There is also evidence that immunisation coverage of highrisk groups increase when vaccination programmes are universal rather than targeted [31,32]. A universal adult pertussis programme not only serves to decrease the overall risk of disease among infants (beyond that which might be achieved with a more focused cocoon strategy), but also to protect adults from the morbidity associated with the disease. Critical to the success of a universal programme is to ensure that adequate pertussis vaccine coverage is achieved. A comparison of various immunisation strategies suggests coverage of at least $40 \%$ within the adult population is required to achieve herd immunity [33]. Unfortunately in the absence of a comprehensive immunisation registry in Ontario, vaccine uptake since the implementation of the universal programme in 2011 is unknown. Routine adult immunisation has been observed to be more cost-effective than a cocoon programme targeting parents [34]. However compared to just an infant immunisation programme, Westra et al. from the Netherlands found that adding maternal immunisation or a cocooning programme for both parents was cost-effective and even cost-saving [35].

This analysis was limited by the sources of data that were available to estimate the overall incidence of disease, hospitalisation and deaths, including lack of agespecific denominator information by month for infants less than four months of age. Due to delays in reporting and under-reporting, the vital statistics database was not used to derive mortality estimates. However, for comparison, three deaths due to pertussis among infants less than one year old were reported in Canada using data from the Vital Statistics database [36].
FIGURE 2

Estimated number needed to vaccinate to prevent (A) one pertussis case, (B) one pertussis hospitalisation, $(\mathrm{C})$ one pertussis death, in an infant less than one year of age, Ontario

A

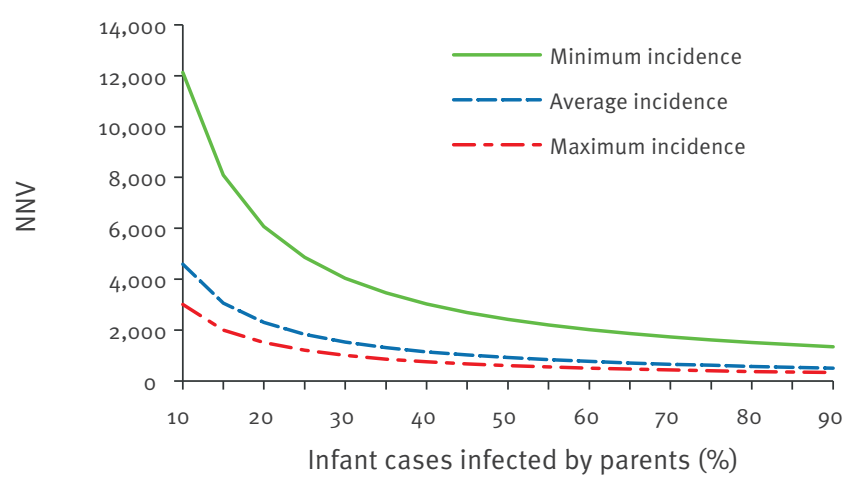

B

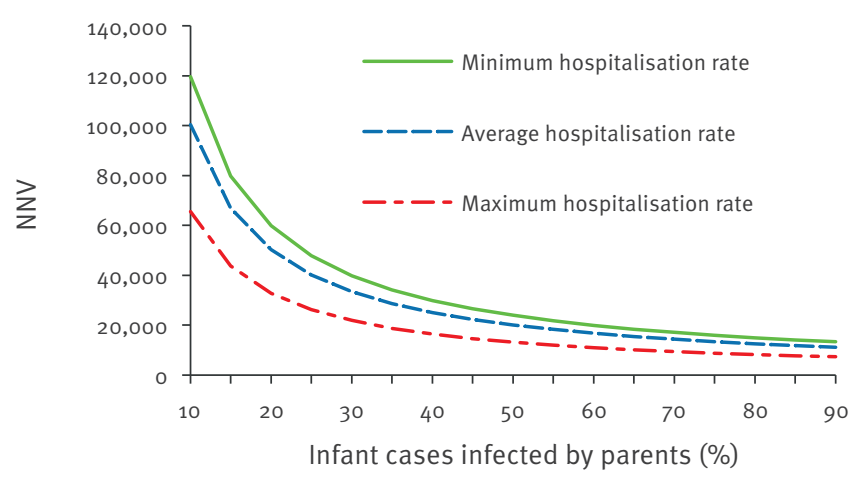

C

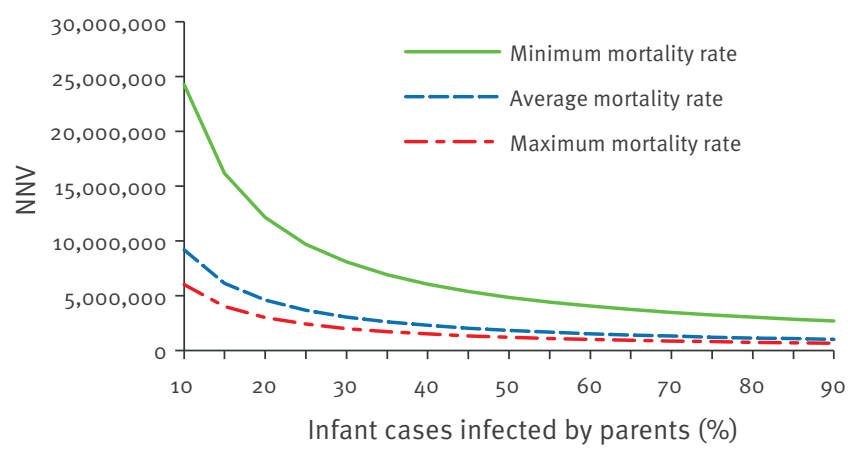

NNV: number needed to vaccinate.

Adjustments for under-reporting were used and mothers were assumed to be twice as likely as fathers to infect the infant in this analysis. 
Extrapolating this to the Ontario population would have resulted in an estimated CFR of $0.03 \%$, whereas the unadjusted CFR estimate used in this analysis was $0.2 \%$. Under-reporting of severe cases of pertussis and deaths has previously been reported $[11,13]$. Inflation factors were assumed to attempt to adjust for underreporting, but true rates were unknown. Despite this, the provision of unadjusted rates in the sensitivity analyses provided a range of estimates for reference. In addition, estimates of the proportion of infants who were infected by the mother or father were derived from several studies using different methodologies. Although these estimates varied between studies, it was reassuring to observe that the relative proportion of infants infected by mothers versus fathers remained generally consistent at a ratio of 2:1.

\section{Conclusion}

This study demonstrates that NNV analyses can incorporate many assumptions and assist when considering implementation of a targeted or universal programme. The NNV estimates derived from this study suggest that a cocoon strategy may or may not be acceptable, depending on the objective of the pertussis vaccination programme. If the objective is to reduce morbidity in the general population, a universal programme might be the most efficient option available. In the current epidemiological situation where pertussis is increasing even in areas with high coverage, and where public health has easier access to parents than to the general adult population, cocooning may be the most feasible or even the only strategy we have to protect infants. What the NNV shows very clearly is the inefficiency inherent in any approach, with relatively large numbers of people to vaccinate in all scenarios. And finally, regardless of approach, a better vaccine is needed, with longer duration of protection that can protect the youngest infants more effectively, preferably through herd immunity.

\section{References}

1. Deeks S, De Serres G, Boulianne N, Duval B, Rochette L, Dery $P$, et al. Failure of physicians to consider the diagnosis of pertussis in children. Clin Infect Dis. 1999;28(4):840-6. http:// dx.doi.org/10.1086/515203

2. von König $\mathrm{CH}$, Halperin S, Riffelmann M, Guiso N. Pertussis of adults and infants. Lancet Infect Dis. 2002 Dec;2(12):744-50. http://dx.doi.org/10.1016/S1473-3099(02)00452-8

3. Crowcroft NS, Stein C, Duclos P, Birmingham M. How best to estimate the global burden of pertussis? Lance Infect Dis. 2003;3(7):413-8. http://dx.doi.org/10.1016/ S1473-3099(03)00669-8

4. Kwong JC, Crowcroft NS, Campitelli MA, Ratnasingham S, Daneman N, Deeks SL, et al. Ontario Burden of Infectious Disease Study Advisory Group; Ontario Burden of Infectious Disease Study (ONBOIDS): An OAHPP/ICES Report. Toronto: Ontario Agency for Health Protection and Promotion, Institute for Clinical Evaluative Sciences; 2010.

5. Public Health Ontario (PHO). Summary of immunization coverage for Ontario school pupils, 2011/12 school year. Monthly Infectious Diseases Surveillance Report. 2013; 2(12):7-10. Available from: http://www.publichealthontario.ca/ en/DataAndAnalytics/Documents/PHO Monthly_Infectious Diseases_Surveillance_Report_-_December_2013.pdf

6. Jardine A, Conaty SJ, Lowbride C, Staff M, Vally. Who gives pertussis to infants? Source of infection for laboratory confirmed cases less than 12 months of age during an epidemic, Sydney, 2009. Commun Dis Intell. 2010;34(2):116-21.
7. Elliott E, Ridley G, Morris A, Massie J, McEniery J, Knight G. National study of infants hospitalised with pertussis in the acellular vaccine era. Pediatr Infect Dis J. 2004;23(3):246-52. http://dx.doi.org/10.1097/01.inf.0000116023.56344.46

8. De Greeff SC, Mooi FR, Westerhof A, Verbakel JMM, Peeters MF, Heuvelman CJ, et al. Pertussis disease burden in the household: How to protect young infants. Clin Infect Dis 2010;50(10):1339-45. http://dx.doi.org/10.1086/652281

9. Halperin SA, Wang EEL, Law B, Mills E, Morris R, Dery P, et al. Epidemiological features of pertussis in hospitalised patients in Canada, 1991-1997: Report of the Immunization Monitoring Program-Active (IMPACT). Clin Infect Dis. 1999;28(6):1238-43. http://dx.doi.org/10.1086/514792

10. Bisgard KM, Pascual FB, Ehresmann KR, Miller CA, Cianfrin $C$, Jennings CE, et al. Infant pertussis: Who was the source? Pediatr Infect Dis J. 2004;23(11):985-9. http://dx.doi. org/10.1097/01.inf.0000145263.37198.2b

11. Vitek CR, Pascual FB, Baughman AL, Murphy TV. Increase in deaths from pertussis among young infants in the United States in the 1990s. Pediatr Infect Dis J. 2003;22(7):628-34. http://dx.doi.org/10.1097/01.inf.0000073266.30728.0e

12. Wendelboe AM, Njamkepo E, Bourillon A, Floret DD, Gaudelus J, et al. Transmission of Bordetella pertussis to young infants. Pedatr Infect Dis J. 2007;26(4):293-9. http://dx.doi. org/10.1097/01.inf.0000258699.64164.6d

13. Crowcroft NS, Booy R, Harrison T, Spicer L, Britto J, Mok $Q$, et al. Severe and unrecognised: pertussis in UK infants. Arch Dis Child. 2003;88(9):802-6. http://dx.doi.org/10.1136/ adc.88.9.802

14. Bonmarin I, Levy-Bruhl D, Baron S, Guiso N, Njamkepo E, Caro V. Pertussis surveillance in French hospitals: Results from a 10 year period. Euro Surveill. 2007;12(1):34-8.

15. Baron S, Niamkep E, Grimprel E, Begue P, Desenclos J-C, Drucker J, et al. Epidemiology of pertussis in French hospitals in 1993 and 1994: thirty years after a routine use of vaccination. Pediatr Infect Dis J. 1998; 17(5):412-8. http:// dx.doi.org/10.1097/00006454-199805000-00013

16. Wiley KE, Zuo Y, Macartney KK, McIntyre PB. Sources of pertussis infection in young infants: A review of key evidence informing targeting of the cocoon strategy. Vaccine. 2012:31(4):618-25. http://dx.doi.org/10.1016/j. vaccine.2012.11.052

17. Centers for Disease Control and Prevention. Updated recommendations for use of tetanus toxoid, reduced diphtheria toxoid, and acellular pertussis vaccine (Tdap) in pregnant women - Advisory Committee on Immunization Practices (ACIP), 2012 MMWR Morb Mortal Wkly Rep. 2013:62(7):131-5.

18. National Advisory Committee on Immunization. Prevention of pertussis in adolescents and adults. Can Commun Dis Rep. 2003;29:1-9.

19. Canadian Institute for Health Information (CIHI). International Statistical Classification of Disease and Related Health Problems, Tenth Revision, Canadian Enhancement (ICD-10-CA). Toronto: Canada; 2009. Available from: http://www.cihi.ca/ cihi-ext-portal/pdf/internet/icd_10_ca_vol1_2009_en

20. De Serres G, Skowronski DM, Mimault P, Ouakki M, Maranda-Aubut R, Duval B. Bats in the bedroom, bats in the belfry: Reanalysis of the rationale for rabies postexposure prophylaxis. Clin Infect Dis. 2009;48(11):1493-9. http://dx.doi. org/10.1086/598998

21. Crowcroft NS. Protecting contacts of hepatitis A: what's the difference between vaccine and human normal immunoglobulin? Epidemiol Infect. 2008;136(1):10-3. http:// dx.doi.org/10.1017/S0950268807008242

22. Kelly H, Attia J, Andrews R, Heller RF. The number needed to vaccinate (NNV) and population extensions of the NNV: comparison of influenza and pneumococcal vaccine programmes for people aged 65 years and over. Vaccine. 2004;22(17-18):2192-8. http://dx.doi.org/10.1016/j. vaccine.2003.11.052

23. Brisson M. Estimating the number needed to vaccinate to prevent herpes zoster-related disease, health care resource use and mortality. Can J Public Health. 2008;99(5):383-6.

24. Brisson M, Van de Velde N, De Wals P, Boily M-C. Estimating the number needed to vaccinate to prevent diseases and death related to human papillomavirus infection. Can Med Assoc J. 2007;177(5):464-8. http://dx.doi.org/10.1503/cmaj.061709

25. Lewis EN, Griffin MR, Szilagyi PG, Zhu Y, Edwards KM, Poehling KA. Childhood influenza: number needed to vaccinate to prevent 1 hospitalization or outpatient visit. Pediatrics. 2007; 120(3):467-72. http://dx.doi.org/10.1542/peds.2007-0167

26. Van Rie A, Hethcote HW. Adolescent and adult pertussis vaccination: computer simulations of five new strategies. Vaccine. 2004;22(22-23):3154-65. http://dx.doi.org/10.1016/j. vaccine.2004.01.067 
27. Skowronski DM, Janjua NZ, Tsafack EPS, Ouakki M, Hoang L, De Serres G. The number needed to vaccinate to prevent infant pertussis hospitalization and death through parent cocoon immunization. Clin Infect Dis. 2012;54(3):318-27. http://dx.doi. org/10.1093/cid/cir836

28. Meregaglia M, Ferrara L, Melegara A, Demicheli V. Parent 'cocoon' immunization to prevent pertussis-related hospitalization in infants: The case of Piemonte in Italy. Vaccine. 2013:31(8):1135-7. http://dx.doi.org/10.1016/j. vaccine.2012.12.061

29. Winter K, Harriman K, Schechter R, Chang J, Talarico J. Effectiveness of postpartum Tdap vaccination in California hospitals. Presented at the Council of State and Territorial Epidemiologists (CSTE) 2010 Annual Conference; 2010 Jun; Portland, OR, USA.

30. Castagnini LA, Healy CM, Rench MA, Wootton SH, Munoz FM, Baker CJ. Impact of maternal postpartum tetanus and diphtheria toxoids and acellular pertussis immunization on infant pertussis infection. Clin Infect Dis. 2012;54(1):78-84. http://dx.doi.org/10.1093/cid/cir765

31. Al-Sukhni W, Avarino P, McArthur MA, McGeer A. Impact of public vaccination programs on adult vaccination rates: Two examples from Ontario, Canada. Vaccine. 2008;26(11):1432-7. http://dx.doi.org/10.1016/j.vaccine.2008.01.001

32. Kwong JC, Sambell C, Johansen H, Stukel TA, Manuel DG. The effect of universal influenza immunization on vaccination rates in Ontario. Health Rep. 2006;17(2):31-40.

33. Coudeville L, Van Rie A, Andre P. Adult pertussis vaccination strategies and their impact on pertussis in the United States: evaluation of routine and targeted (cocoon) strategies.

Epidemiol Infect. 2008;136:604-20. http://dx.doi.org/10.1017/ So950268807009041

34. Coudeville L, Van Rie A, Getsios D, Caro JJ, Crepey P, Nguyen VH. Adult vaccination strategies for the control of pertussis in the United States: An economic evaluation including the dynamic population effects. PLos One. 2009;4(7):e6284. http://dx.doi.org/10.1371/journal.pone.0006284

35. Westra TA, de Vries R, Tamminga JJ, Sauboin CJ, Postma MJ. Cost-effectiveness analysis of various pertussis vaccination strategies primarily aimed at protecting infants in the Netherlands. Clin Ther. 2010;32(8):1479-95. http://dx.doi. org/10.1016/j.clinthera.2010.07.017

36. CANSIM [Internet]. Ottawa: Statistics Canada. Table 102 0521 - Deaths, by cause, Chapter I: Certain infectious and parasitic diseases (Aoo to B99), age group and sex, Canada 2005-2009. [Accessed 26 Nov 2013]. Available from: http:// www5.statcan.gc.ca/cansim/a26?lang=eng\&retrLang= eng \&id $=1020521 \&$ paSer $=\&$ pattern $=\&$ stByVal $=1 \&$ p $1=1$ $\& p 2=-1 \&$ tabMode $=$ dataTable $\&$ csid $=$ 